\title{
Impact of Cognitive and Social Factors on Smoking Cessation Attempts among US Adult Muslim Smokers
}

Omar Attarabeen, RPh, PhD ; Fadi Alkhateeb, PhD²; Usha Sambamoorthi, PhD ; Kevin Larkin, PhD ${ }^{4}$; Michael Newton, PharmD ; Kimberly Kelly, $P h D^{3}$

${ }^{1}$ Department of Pharmacy Practice, Research, \& Administration, School of Pharmacy, Marshall University

2 Department of Pharmacy Practice, South College School of Pharmacy, Knoxville, TN

${ }^{3}$ Robert C. Byrd Health Sciences Center (North), Department of Pharmaceutical Systems \& Policy, West Virginia University

${ }^{4}$ Department of Psychology, Eberly College of Arts \& Sciences, Life Sciences Building, West Virginia University

${ }^{5}$ Robert C. Byrd Health Sciences Center (North), Department of Clinical Pharmacy, West Virginia University

\begin{abstract}
Background. Muslims in the United States (US) exhibit high rates of cigarette smoking. Guided by the Social Cognitive Theory, the study aimed to investigate the associations between the number of serious cigarette smoking cessation attempts and cognitive as well as environmental factors in adult US Muslim smokers.

Methods. This cross-sectional study was based on a convenience sample of adult ( $\geq 18$ years) US Muslim smokers. After receiving IRB approval, data were collected using an on-line survey. Unadjusted Poisson regression followed by adjusted multivariable Poisson regression analyses were conducted to answer the research question.

Results. One hundred thirty-two smokers completed the questionnaire. Smokers reported more serious cigarette smoking cessation attempts if they 1) had more knowledge about the consequences of cigarette smoking cessation, 2) had more positive attitudes regarding quitting, and 3) reported greater religiosity. Additionally, smokers reported fewer serious cigarette smoking cessation attempts if they 1) were employed, 2) affiliated with Sunnah sect, 3) reported better self-assessed health, 4) reported higher perceived value for quitting, and 5) indicated that using tobacco was not allowed inside the home. Only three smokers reported using both prescription medications and counseling to aid with smoking cessation attempts.

Conclusions. Inadequate utilization of pharmaceutical smoking cessation products and provider professional assistance may exacerbate the problems associated with elevated rates of smoking among US Muslim smokers. Knowledge of the consequences, more positive attitudes, and greater religiosity can be influential constructs in future interventions aimed at encouraging smoking cessation attempts in this population.
\end{abstract}

Keywords: Muslims, Cognitive Factors, Environmental Factors, Quitting Smoking, Religiosity, Acculturation

\section{Introduction}

Quitting cigarette smoking is associated with major health benefits, such as improved cardiovascular and respiratory functions. ${ }^{1}$ A greater number of serious smoking cessation attempts (SSCA), defined as abstaining from cigarette-smoking for one day or longer while attempting to quit, ${ }^{2}$ is associated with greater chances of successful cigarette-smoking cessation. ${ }^{3}$ In 2015, 55\% of cigarette smokers in the United States (US) had at least one SSCA over the past 12 months, but only $7 \%$ of them succeeded in quitting. ${ }^{2}$ Thus, it is suggested that promoting smoking cessation could be achieved by encouraging more quit attempts. ${ }^{4}$ In fact, it takes a cigarette smoker between 6 and 142 quit attempts to achieve successful cessation. ${ }^{3}$ Therefore, investigating the number of SSCA is essential to identify factors that promote smoking cessation.

Corresponding author: Omar Attarabeen, RPh, PhD

Department of Pharmacy Practice, Research \& Administration School of Pharmacy, Marshall University

One John Marshall Drive, Huntington, WV 25755

Phone: 304-696-6019; Fax: 304-696-7309

ORCID iD: 0000-0001-7548-3404

E-Mail: attarabeen@marshall.edu
Previous research demonstrated that more frequent SSCA is associated with higher self-efficacy regarding the ability to quit smoking, ${ }^{5}$ perceived social pressure due to interacting with nonsmokers, ${ }^{6}$ lower acculturation, ${ }^{7}$ living in a smoke-free home,${ }^{8}$ discussing smoking cessation with physicians, ${ }^{9}$ more nicotine dependence, ${ }^{10}$ being male, ${ }^{11}$ and having a high school education or higher. ${ }^{11}$ Additionally, previous research demonstrated that the number of SSCA could be influenced by several cognitive and environmental factors, ${ }^{2}$ especially among minority groups. ${ }^{12}$ As a minority group in the US, the Muslim population ranges between 3 and 7 million, ${ }^{13,14}$ the majority $(63 \%)$ of whom are foreign-born. ${ }^{15}$ Although Islamic Jurisprudence entities consider cigarette-smoking to be forbidden in Islam, ${ }^{16}$ Muslims exhibit elevated cigarettesmoking rates in the US ${ }^{17,18}$ and around the world, ${ }^{19}$ which places them at a higher risk of preventable disease and premature death compared to the remaining US population.

The Social Cognitive Theory (SCT) was used to investigate the factors associated with the number of SSCA. ${ }^{20}$ The SCT suggests that behavior depends on the interaction among several cognitive and environmental factors. Cognitive factors include 5 constructs: 1) knowledge of the general consequences of 
cigarette-smoking cessation, 2) personal expectations of the impact of cigarette-smoking cessation on health, 3) perceived value of this health impact, 4) attitudes (i.e., overall opinion) regarding cigarette-smoking cessation, and 5) self-efficacy regarding one's ability to quit smoking. In contrast, environmental factors include 3 constructs: 1) vicarious learning, 2) social norms surrounding quitting smoking, and 3) barriers and facilitators related to quitting smoking. ${ }^{21-23}$ In addition, acculturation and religiosity are key concepts within social norms. Acculturation assesses how assimilated immigrants are with the main culture of their new environment, ${ }^{24}$ whereas religiosity measures the level of compliance of individuals with their own religious beliefs and practices.

Despite the importance of human agency in health behavior, ${ }^{25}$ social norms can be key determinants of smoking behavior in Muslims. For example, tobacco use is socially accepted and may promote social interaction in some predominantly Muslim countries. ${ }^{26}$ Additionally, religiosity was noted as an important factor in smoking cessation attempts, ${ }^{27}$ especially among Muslims. ${ }^{28}$ However, gender-specific analysis has shown that weekly attendance of religious services was associated with more likelihood of quitting cigarette-smoking only in women. ${ }^{27}$ In sum, due to its inclusion of pertinent psychosocial factors, utilizing the SCT was appropriate for analyzing factors associated with SSCA among US Muslim smokers.

Because the majority of US Muslims are foreign-born, ${ }^{15}$ they may have different cognitive and social characteristics affecting their cigarette-smoking cessation than other US citizens. Prior to this research, there was a gap in the literature regarding associations between the number of SSCA and Social Cognitive Theory (SCT) factors in US Muslim smokers. Thus, the current study investigated the SCT factors that are associated with the number of SSCA in a sample of adult US Muslim smokers. The overarching hypothesis was that adult Muslim smokers would have more SSCA if they exhibit favorable cognitive and social factors according to the SCT. Additionally, the study examined the interaction effect of sex and religiosity on the number of SSCA. The hypothesis was that sex would moderate the association between religiosity and the number of serious attempts to quit cigarette smoking.

\section{Methods}

Design

The dataset used to test the hypotheses was part of a larger cross-sectional design study. ${ }^{18}$ This dataset was based on a quantitative online survey that was deployed January to March of 2017, and collected data from 370 participants to assess the factors that are associated with the use of tobacco products, including cigarettes, cigars, and water-pipes (i.g., hookah). However, this project was restricted to participants who reported current cigarette smoking. The study included a convenience sample of adult ( $\geq 18$ years old) US Muslim smokers. Due to potentially different cigarette-smoking cessation behaviors, 2 smokers with a personal history of lung cancer were excluded from the analyses. Lung cancer patients were excluded because they may have fundamentally different behaviors concerning tobacco use, perhaps due to greater interaction with health care providers. The Office of Research Integrity and Compliance has reviewed and determined the research to be exempt.

\section{Measures}

The primary variable of interest was assessed using one item that inquired about the number of SSCA during the past 12 months. SSCA was defined as abstaining from smoking for one day or longer as an attempt to quit smoking. ${ }^{2}$ Because only participants who reported current cigarette smoking were included in the study, eligible participants were those who 1) smoked a total of at least 100 cigarettes in their entire life, and 2) reported current smoking 'some days' or 'every day', consistent with the definition of current smoking in previous research. ${ }^{29}$ Pertinent constructs from the SCT were measured following previous research, ${ }^{30-36}$ and are presented in Table 1. Acculturation was measured using the Brief Acculturation Scale, ${ }^{37}$ which is a 4 -item scale that measures language preference, self-identity, country where participants spent childhood, and place of birth. This scale has demonstrated good internal consistency ( $\alpha=0.84$ ) in previous research. ${ }^{37}$ Religiosity was measured using the Duke University Religion Index, ${ }^{38}$ which is a 5-item scale that demonstrated high internal consistency in previous research $(\alpha=0.87) .{ }^{39}$ Responses to acculturation and religiosity were normalized to range from zero to 100 as explained in the original study. ${ }^{18}$ In terms of barriers and facilitators, nicotine dependence was measured using the Heavy Smoking Index, a 2-item scale with high concordance with Fagerström Nicotine Dependence Scale. ${ }^{40}$ Discussing cigarette-smoking cessation with a physician anytime over the past 12 months (No/Yes) and rules of using tobacco inside the home (Not allowed/Allowed) were assessed using one item for each as described previously. ${ }^{18}$ Finally, use of cigarette-smoking cessation techniques was measured using a multiple-answer item. Responses included 1) nicotine replacement, 2) prescription medications, 3) behavioral support, and 4) no pharmaceutical/behavioral assistance. Lastly, demographic characteristics, including sex, age, race, ethnicity, marital status, education, employment status, income, health insurance status, and general well-being were measured using one item for each as explained previously. ${ }^{18}$

\section{Statistical Analysis}

Descriptive analyses were conducted to identify the distribution of categorical variables with regard to SSCA. Due to lack of sufficient distribution, some variables were collapsed into binary variables, as explained in the original study. ${ }^{18}$ In order to examine associations with the primary variable of interest (i.e., number of SSCA), cognitive and environmental variables as well as demographic variables were investigated using 2 Poisson regression models, individually in an unadjusted model and collectively in an adjusted model. We used this type 
of regression due to the distinct binomial distribution of the primary variable of interest (i.e., SSCA). Because it is used to model count data, and because of rare large counts found in the distribution of SSCA variable, Poisson regression was determined to be the most applicable to answer the research question. Secondary independent samples $t$-test was conducted to identify whether men and women varied in religiosity. Finally, a Poisson regression analysis was conducted to examine the potential interaction between the sex of respondents and religiosity on number of SSCA.

\section{Results}

Because this research study was part of a larger study, ${ }^{18}$ there was a total of 370 responses. However, only 132 participants met the eligibility criteria for this study (4 participants younger than 18 years old, 61 participants from outside the US, 25 participants did not affiliate with Islam, 8 participants had a personal history of lung cancer, one duplicate record, and 139 did not report current cigarette-smoking). Eligible participants completed the questionnaire in English ( $n=91)$, Arabic $(n=40)$, and Farsi $(n=1)$. Participants' age ranged from 19 to 68, with a mean age of 37. Only one participant was Hispanic or Latino/a. The majority (59\%) of participants were foreign-born. Only $47 \%$ of the sample of smokers attempted to quit smoking seriously at least once over the past 12 months. This rate was slightly lower, but not statistically significant $(t(131)=-1.933, p=.055)$ from the most recently reported rate of annual quit attempts among US smokers (55\%). ${ }^{2}$

The number of quit attempts ranged from zero to 30 , with a mean value of 1.56 . Out of 62 smokers in the sample with at least one SSCA, only 3 smokers reported using both prescription medications and counseling to aid with SSCA. Additionally, 24 smokers reported using nicotine replacement, 31 smokers reported not using any form of assistance, and the rest reported using either prescription medications or counseling. Variables that were significantly associated with the number of SSCA in the unadjusted Poisson regression model are presented in Table 2.

In adjusted Poisson regression analyses, significant associations were observed between some SCT factors and the number of SSCA (Table 3). With regard to cognitive factors, knowledge was positively associated with SSCA; those who perceived a higher reduction in chances of diseases or death as a result of quitting smoking had $41 \%$ higher number of SSCA (adjusted incident rate ratio $(A I I R)=1.405 ; 95 \%$ confidence interval $(C I)=1.098-$ 1.798). Similarly, smokers who had more positive views on cigarette-smoking cessation had 51\% higher number of SSCA compared to those with negative views on cigarette-smoking cessation (AIIR $=1.513 ; 95 \% \mathrm{Cl}=1.122 ; 2.041$ ). However, those with a higher perceived value of cigarette-smoking cessation had $26 \%$ lower number of SSCA (AIIR $=0.744 ; 95 \% \mathrm{Cl}: 0.562-$ 0.985).
In terms of environmental factors, religiosity and tobacco use inside the home were significantly associated with SSCA. Higher scores on religiosity scale were associated with $1 \%$ higher number of SSCA (AIIR = 1.011; $95 \% \mathrm{Cl}=1.002,1.020$ ). However, those who lived in homes where tobacco use was not allowed had 53\% lower number of SSCA compared to smokers who lived in homes where tobacco use was allowed (AIIR $=0.473 ; 95 \% \mathrm{Cl}$ $=0.299-0.750)$.

Among the demographic factors, employment status, sect affiliation, and general well-being were associated with SSCA. Employed individuals had 53\% lower SSCA compared to those who were not employed (AIIR $=0.467 ; 95 \% \mathrm{Cl}=0.299-0.727$ ). Smokers who reported affiliation with Sunnah sect had $51 \%$ lower number of SSCA compared to smokers who did not affiliate with Sunnah sect (AIIR $=0.485 ; 95 \% \mathrm{Cl}=0.318-0.740)$. Finally, smokers who reported better perceived well-being had $1 \%$ lower number of SSCA (AIIR $=0.986 ; 95 \% \mathrm{Cl}=0.977-0.966$

Secondary analyses demonstrated that men scored higher on religiosity (Mean $(M)=54.9$, Standard deviation $(S D)=33.9$ ) compared to women ( $M=19.2, S D=23.8), t(130)=-6.489, p<$ .001 . However, the interaction between sex of respondent and religiosity in association with SSCA was not statistically significant $(p=.932)$.

\section{Discussion}

The associations between SSCA and knowledge of the consequences as well as attitudes were consistent with previous research. ${ }^{33,41}$ If based on the SCT, future interventions targeting this population may address techniques to stop smoking and to seek professional assistance. Because $59 \%$ of the participants were foreign-born, their past education before immigrating to the US may not have equipped them with sufficient knowledge about the consequences of smoking. This highlights the importance of effective patient-provider communication in this regard. Additionally, few participants reported nicotine replacement use, which again, might be related to little knowledge about smoking cessation. Contrary to the hypothesis, smokers who reported a higher perceived value of smoking cessation had fewer SSCA. One explanation might be that quit attempts last longer in smokers with a higher perceived value of smoking cessation, and therefore, a fewer number of quit episodes are attempted during a 12-month period.

The role of religiosity in promoting cigarette-smoking cessation was documented in previous research on Muslim smokers outside the US, ${ }^{28}$ as well as in this study. Higher religiosity may have been observed as higher compliance with religious rulings related to abstaining from harmful substances. ${ }^{42}$ Therefore, religion-based messages might hold promise for encouraging SSCA in US Muslim smokers. However, because men scored higher on the religiosity scale compared to women, this finding should be interpreted with caution. Future research may examine the potential moderating effect of sex on religiosity. 
Contrary to previous research linking no smoking in the home to more smoking cessation attempts, ${ }^{8,43}$ the findings of this study demonstrated that smokers who reported living in smoke-free homes had fewer SSCA. Due to not exposing their family members to secondary smoking, smokers who live in smoke-free homes may have less motivation to quit. Another interpretation might be that smokers who live in smokingfriendly homes perceive greater health risk, possibly combined with the smoking of others, and therefore, they exert more effort to quit smoking.

It has been reported that discussing cigarette-smoking cessation with health care providers facilitates cigarettesmoking cessation attempts. ${ }^{44}$ However, 27 smokers (21\%) reported that no health care providers had asked them about quitting smoking over the past 12 months, either because they did not see a health care provider during the 12 months period before data collection, or because they failed to discuss cigarette-smoking cessation during health care encounters. In addition, although combination therapy (prescription plus counseling) has shown the highest effectiveness rates for successful cigarette-smoking cessation, ${ }^{44}$ only 3 smokers reported using both techniques to help with quit attempts. In sum, limited assistance from health care providers might be a barrier to curbing smoking rates among this population.

Some demographic factors were also associated with the number of SSCA. Employed individuals had lower SSCA compared to those who were not employed. This could be interpreted as employed individuals choosing not to endure withdrawal symptoms due to work-related stress or because employed smokers do not have the time to invest in seeking medical or behavioral assistance to quit smoking. More research is needed to address this relationship in the future. Finally, smokers with worse self-assessed health reported more SSCA. Although causation cannot be implied, it is possible that those with lower self-assessed health may be acting to improve their health status by attempting to quit smoking.

The current study had some limitations. First, using convenience sampling techniques limits the generalizability of these results to all adult US Muslim smokers. Second, because participation was voluntary and data were collected online, the response rate could not be enumerated, and consequently, rates of non-response remain unknown. Third, the crosssectional design hinders the ability to investigate causal relations for any of the observed associations. Fourth, the rules of tobacco use at the workplace were not measured. This may have limited the capability to fully understand the association observed between employment status and the number of SSCA. Finally, we utilized single-item measures, which may result in limited validity for the results. Nevertheless, data was collected from smokers in 23 states in the US, so the findings are not confined to a particular region of the country. Additionally, this was the first study to investigate the associations between SSCA and cognitive as well as environmental factors among adult US Muslim smokers using the SCT.

\section{Conclusion}

The current study investigated the SCT factors related to the number of SSCA in a sample of adult Muslim smokers in the US. The majority of participants (63\%) were men, which is typical, considering the higher likelihood of cigarette-smoking in Muslim men compared to Muslim women. ${ }^{45}$ In the study sample, $47 \%$ of smokers attempted to quit at least once during the 12 months period prior to data collection. This is slightly lower than the national rate of quit attempts, which was $55 \%$ in $2015 .^{2}$ Researchers who address smoking cessation in adult US Muslim smokers should bear in mind two important implications for this study. First, more SSCA is associated with more knowledge of the consequences, more positive attitudes, and greater religiosity, all of which can be used to build future cigarette-smoking cessation interventions. Second, inadequate utilization of pharmaceutical smoking cessation products and provider professional assistance among US Muslim smokers may exacerbate the problems associated with elevated rates of smoking in this population.

Disclosure statements: Authors declare no conflicts of interest. This research did not receive any specific grant from funding agencies in the public, commercial, or not-for-profit sectors.

Acknowledgement: Thanks to Omar Abu Abed, Simin Falsafi, Ali Fakhimi, and Maleeha Hassan for assisting in translating the questionnaire.

\section{References}

1. Gratziou C. Respiratory, cardiovascular and other physiological consequences of smoking cessation. Current Medical Research and Opinion. 2009;25(2):535-545.

2. Babb S. Quitting smoking among adults-United States, 2000-2015. Morbidity and Mortality Weekly Report. 2017;65.

3. Chaiton M, Diemert L, Cohen JE, et al. Estimating the number of quit attempts it takes to quit smoking successfully in a longitudinal cohort of smokers. BMJ. 2016;6(6):e011045.

4. Gilbert H, Nazareth I, Sutton S, et al. Effectiveness of computer-tailored smoking cessation advice in primary care (ESCAPE): a randomised trial. Trials. 2008;9(1):23.

5. John U, Meyer C, Rumpf H-J, et al. Self-efficacy to refrain from smoking predicted by major depression and nicotine dependence. Addictive Behaviors. 2004;29(5):857-866.

6. Burns D. Tobacco use in California 1990-1991. DIANE Publishing; 2009. 
7. Haddad L, El-Shahawy O, Shishani K, et al. Cigarette use attitudes and effects of acculturation among Arab immigrants in USA: a preliminary study. Health. 2012;4(10):785-793.

8. Borland $\mathrm{R}$, Yong $\mathrm{HH}$, Cummings $\mathrm{KM}$, et al. Determinants and consequences of smoke-free homes: findings from the international tobacco control four country survey. Tobacco Control. 2006;15 Suppl 3:iii42-50.

9. Aveyard P, Begh R, Parsons A, at al. Brief opportunistic smoking cessation interventions: a systematic review and meta-analysis to compare advice to quit and offer of assistance. Addiction. 2012;107(6):1066-1073.

10. John U, Meyer C, Hapke U, et al. Nicotine dependence, quit attempts, and quitting among smokers in a regional population sample from a country with a high prevalence of tobacco smoking. Preventive Medicine. 2004;38(3):350-358.

11. Ferron JC, Brunette MF, He X, et al. Course of smoking and quit attempts among clients with cooccurring severe mental illness and substance use disorders. Psychiatric Services. 2011;62(4):353-359.

12. Fu SS, Burgess $D$, van Ryn $M$, et al. Views on smoking cessation methods in ethnic minority communities: a qualitative investigation. Preventive Medicine. 2007;44(3):235-240.

13. Kettani H. Muslim Population in the Americas. Population. 2010:2020.

14. Mohamed B. A new estimate of the U.S. Muslim population. Washington, DC: Pew Research Center;2016. Available at: https://www.pewresearch.org/facttank/2016/01/06/a-new-estimate-of-the-u-s-muslimpopulation/. Accessed on September 3, 2020.

15. Kohut, A., Keeter, S, Smith, G., et al. Muslim Americans: no signs of growth in alienation or support for extremism. Pew Research Center. 2011. Available at https://www.pewresearch.org/politics/2011/08/30/ muslim-americans-no-signs-of-growth-in-alienationor-support-for-extremism/. Accessed on September 3, 2020.

16. World Health Organization. Islamic ruling on smoking. 2000; Available at:

https://apps.who.int/iris/handle/10665/119631. Accessed on September 3, 2020.

17. Newport F, Himelfarb I. In U.S., strong link between church attendance, smoking. Gallup Incorporation;2013. Available at https://news.gallup.com/poll/163856/strong-linkchurch-attendancesmoking.aspx\#: :text=PRINCETON\%2C\%20NJ\%20\%2D \%2D\%20Smoking\%20in, with\%20smoking\%20and\%20 church\%20attendance. Accessed on September 3, 2020.
18. Attarabeen $O$, Alkhateeb F, Larkin K, Sambamoorthi $\mathrm{U}$, Newton M, Kelly KM. Tobacco Use among a Sample of Adult Muslims in the United States. Substance Use \& Misuse. 2019;54(8):1385-1399.

19. Ghouri N, Atcha M, Sheikh A. Influence of Islam on smoking among Muslims. British Medical Journal. 2006;332(7536):291-294.

20. Bandura A. Social foundations of thought and action: A social cognitive theory. Prentice-Hall, Inc; 1986.

21. Bandura A. Health promotion from the perspective of social cognitive theory. Psychology and Health. 1998;13(4):623-649.

22. Bandura A. Social cognitive theory of mass communication. Media Psychology. 2001;3(3):265299.

23. Bandura A. The primacy of self-regulation in health promotion. Applied Psychology. 2005;54(2):245-254.

24. Hui K, Lent RW, Miller MJ. Social cognitive and cultural orientation predictors of well-being in Asian American college students. Journal of Career Assessment. 2013;21(4):587-598.

25. Bandura A. Human agency in social cognitive theory. American Psychologist. 1989;44(9):1175.

26. Unger JB, Cruz T, Shakib S, et al. Exploring the cultural context of tobacco use: a transdisciplinary framework. Nicotine \& Tobacco Research. 2003;5 Suppl 1:S101-117.

27. Strawbridge WJ, Shema SJ, Cohen RD, et al. Religious attendance increases survival by improving and maintaining good health behaviors, mental health, and social relationships. Annals of Behavioral Medicine. 2001;23(1):68-74.

28. Yong $\mathrm{H}-\mathrm{H}$, Savvas $\mathrm{S}$, Borland R, et al. Secular versus religious norms against smoking: which is more important as a driver of quitting behaviour among Muslim Malaysian and Buddhist Thai smokers? International Journal of Behavioral Medicine. 2013;20(2):252-258.

29. U.S. Department of Health and Human Services. National Health Interview Survey, survey description. 2019. Available at:

ftp://ftp.cdc.gov/pub/Health_Statistics/NCHS/Datase t_Documentation/NHIS/2018/srvydesc.pdf. Accessed on September 3, 2020.

30. Flay BR, Hu FB, Siddiqui O, et al. Differential influence of parental smoking and friends' smoking on adolescent initiation and escalation and smoking. Journal of Health and Social Behavior. 1994:248-265.

31. Borland R, Yong HH, Balmford J, et al. Motivational factors predict quit attempts but not maintenance of smoking cessation: findings from the international tobacco control four country project. Nicotine \& Tobacco Research. 2010;12 Suppl:S4-11. 
32. Shrier LA, Rhoads A, Burke P, Walls C, Blood EA. Realtime, contextual intervention using mobile technology to reduce marijuana use among youth: a pilot study. Addictive Behaviors. 2014;39(1):173-180.

33. Hyland A, Borland R, Li Q, et al. Individual-level predictors of cessation behaviours among participants in the international tobacco control four country survey. Tobacco Control. 2006;15 Suppl 3:iii83-94.

34. Perkins KA, Parzynski $C$, Mercincavage $M$, et al. Is selfefficacy for smoking abstinence a cause of, or a reflection on, smoking behavior change? Experimental and Clinical Psychopharmacology. 2012;20(1):56-62.

35. Kandel DB, Kiros GE, Schaffran C, et al. Racial/ethnic differences in cigarette smoking initiation and progression to daily smoking: a multilevel analysis. American Journal of Public Health. 2004;94(1):128135.

36. Panday S, Reddy SP, Ruiter RA, et al. Determinants of smoking cessation among adolescents in South Africa. Health Education Research. 2005;20(5):586-599.

37. Meredith LS, Wenger N, Liu H, et al. Development of a brief scale to measure acculturation among Japanese Americans. Journal of Community Psychology. 2000;28(1):103-113.

38. Koenig HG, Büssing $A$. The duke university religion index (DUREL): a five-item measure for use in epidemological studies. Religions. 2010;1(1):78-85.

39. Saffari M, Zeidi IM, Pakpour AH, et al. Psychometric properties of the Persian version of the duke university religion index: a study on Muslims. Journal of Religion and Health. 2013;52(2):631-641.

40. Chabrol H, Niezborala M, Chastan E, et al. Comparison of the heavy smoking index and of the Fagerstrom test for nicotine dependence in a sample of 749 cigarette smokers. Addictive Behaviors. 2005;30(7):1474-1477.

41. Davila EP, Zhao W, Byrne M, et al. Correlates of smoking quit attempts: Florida tobacco callback survey, 2007. Tobacco Induced Diseases. 2009;5(10).

42. Hamid MA. Reinterpretation of contemporary Islamic law. JL Pol'y \& Globalization. 2017;61:46.

43. Farkas AJ, Gilpin EA, Distefan JM, et al. The effects of household and workplace smoking restrictions on quitting behaviours. Tobacco Control. 1999;8(3):261265.

44. Stead LF, Lancaster T. Combined pharmacotherapy and behavioural interventions for smoking cessation. Cochrane Database Syst Rev. 2012;10(10).

45. Sayeed S. Tobacco use among Muslims in New York city and surrounding areas: results of the nafis salaam community survey. Journal of the Islamic Medical Association of North America. 2011;43. 
Table 1: Social Cognitive Theory Factors as Utilized in the Study and Measured in the Survey.

\begin{tabular}{lll}
\hline \multicolumn{1}{c}{ Domains and Factors } & \multicolumn{1}{c}{ How Items were Measured in the survey } & How the Scale was Assesed \\
\hline Cognitive factors & & Perceived likelihood of reduction in chances of \\
Knowledge & diseases or death as a result of quitting smoking. & 5-point ordinal scale \\
\cline { 2 - 3 } Outcome Expectations & $\begin{array}{l}\text { Perceived effect of cigarette-smoking cessation on } \\
\text { personal health. }\end{array}$ & 5-point ordinal scale \\
\cline { 2 - 3 } Perceived Value & $\begin{array}{l}\text { Perceived importance of gaining the benefits of } \\
\text { cigarette-smoking cessation. }\end{array}$ & 5-point ordinal scale \\
\cline { 2 - 3 } Attitudes & $\begin{array}{l}\text { Smokers' overall opinions on cigarette-smoking } \\
\text { cessation. }\end{array}$ & 5-point ordinal scale \\
\cline { 2 - 3 } Self-efficacy & $\begin{array}{l}\text { Pecrieved self-confidence regarding ability to quit } \\
\text { smoking. }\end{array}$ & Continuous scale ranging from 0\% \\
& &
\end{tabular}

Environmental factors

Vicarious Learning

Measured through assessing whether smokers knew Yes/No of any former smoker among their first-degree family members and friends

Social Norms

Measured through assessing perceived acceptability 5-point ordinal scale
of quitting smoking among first-degree family
members and friends


Table 2: Descriptive Statistics, Unadjusted Incident Rate Ratio, 95\% Confidence Interval, Standard Error, and Significance Level from Poisson Regression on Number of Serious Cigarette-smoking Cessation Attempts. Muslim Adult ( $\geq 18$ years) Smokers in the United States.

\begin{tabular}{|c|c|c|c|c|c|c|}
\hline & $\mathbf{N}$ & Mean & S.D. & UIRR (95\% CI) & SE & $p$-value \\
\hline \multicolumn{7}{|l|}{ Demographic Characteristics } \\
\hline \multicolumn{7}{|l|}{ Sex } \\
\hline Male & 83 & 2.12 & 3.76 & $3.463(1.756-6.832)$ & 1.200 & $<.001$ \\
\hline Female & 49 & 0.61 & 1.24 & \multicolumn{3}{|c|}{ [Reference] } \\
\hline \multicolumn{7}{|l|}{ Employment Status } \\
\hline Employed & 93 & 1.43 & 3.48 & $0.764(0.414-1.411)$ & 0.239 & .390 \\
\hline Not Employed & 39 & 1.87 & 2.19 & \multicolumn{3}{|c|}{ [Reference] } \\
\hline \multicolumn{7}{|l|}{ Sect } \\
\hline Sunnah & 51 & 2.31 & 4.46 & $2.130(1.125-4.031)$ & 0.693 & .020 \\
\hline Something Else & 81 & 1.09 & 1.81 & \multicolumn{3}{|c|}{ [Reference] } \\
\hline \multicolumn{7}{|l|}{ Health Insurance } \\
\hline No & 14 & 2.21 & 2.01 & $1.493(0.814-2.739)$ & 0.462 & .195 \\
\hline Yes & 118 & 1.48 & 3.26 & \multicolumn{3}{|c|}{ [Reference] } \\
\hline Income & & & & $0.866(0.766-0.979)$ & 0.054 & .021 \\
\hline Age & & & & $0.970(0.951-0.990)$ & 0.010 & .004 \\
\hline Self-assessed Health & & & & $0.988(0.973-1.003)$ & 0.008 & .116 \\
\hline \multicolumn{7}{|l|}{ Cognitive Factors } \\
\hline Knowledge & & & & $1.987(1.681-2.348)$ & 0.169 & $<.001$ \\
\hline Outcome Expectations & & & & $1.876(1.554-2.265)$ & 0.180 & $<.001$ \\
\hline Attitudes & & & & $2.243(1.865-2.697)$ & 0.211 & $<.001$ \\
\hline Perceived Value & & & & $1.708(1.112-2.622)$ & 0.374 & .014 \\
\hline Self-efficacy & & & & $1.025(1.013-1.037)$ & 0.006 & $<.001$ \\
\hline \multicolumn{7}{|l|}{ Environmental Factors } \\
\hline \multicolumn{7}{|l|}{ Vicarious Learning - Family } \\
\hline No & 91 & 1.33 & 3.48 & $0.641(0.343-1.201)$ & 0.205 & .165 \\
\hline Yes & 41 & 2.07 & 2.21 & \multicolumn{3}{|c|}{ [Reference] } \\
\hline \multicolumn{7}{|l|}{ Vicarious Learning - Friends } \\
\hline No & 95 & 1.05 & 1.72 & $0.367(0.191-0.708)$ & 0.123 & .003 \\
\hline Yes & 37 & 2.86 & 5.11 & \multicolumn{3}{|c|}{ [Reference] } \\
\hline Social Norms - Family & & & & $6.177(3.159-12.077)$ & 2.113 & $<.001$ \\
\hline Social Norms - Friends & & & & $2.869(1.783-4.617)$ & 0.696 & $<.001$ \\
\hline Acculturation & & & & $0.988(0.983-0.994)$ & 0.003 & .001 \\
\hline Religiosity & & & & $1.017(1.010-1.024)$ & 0.004 & $<.001$ \\
\hline Nicotine Dependence & & & & $1.458(1.119-1.899)$ & 0.197 & .005 \\
\hline \multicolumn{7}{|l|}{ Tobacco Use Inside Home } \\
\hline Not allowed & 26 & 1.73 & 1.51 & $1.140(0.662-1.962)$ & 0.316 & .637 \\
\hline Allowed & 106 & 1.52 & 3.44 & \multicolumn{3}{|c|}{ [Reference] } \\
\hline \multicolumn{7}{|c|}{ Discuss Cigarette-smoking Cessation with Doctor } \\
\hline No & 27 & 3.15 & 5.68 & $2.732(1.302-5.733)$ & 1.033 & .008 \\
\hline Yes & 105 & 1.15 & 1.91 & \multicolumn{3}{|c|}{ [Reference] } \\
\hline
\end{tabular}

Abbreviations: N, Number of participants included in the analysis, Mean, Mean of the Number of SSCA across Categorical Variables, S.D., Standard Deviation of the Number of SSCA, UIRR, Unadjusted Incident Rate Ratio, Cl, Confidence Interval, SE, Standard Error 
Table 3: Adjusted Incident Rate Ratio, 95\% Confidence Interval, Standard Error, and Significance Level from Poisson Regression on Number of Serious Cigarette-smoking Cessation Attempts. Muslim Adult ( $\geqq 18$ years) Smokers in the United States.

\begin{tabular}{|c|c|c|c|}
\hline & AIRR (95\% CI) & SE & $p$-value \\
\hline \multicolumn{4}{|l|}{ Demographic Characteristics } \\
\hline \multicolumn{4}{|l|}{ Sex } \\
\hline Male & $1.682(0.951-2.976)$ & 0.490 & .074 \\
\hline Female & \multicolumn{3}{|c|}{ [Reference] } \\
\hline \multicolumn{4}{|l|}{ Employment Status } \\
\hline Employed & $0.467(0.299-0.727)$ & 0.106 & .001 \\
\hline Not Employed & \multicolumn{3}{|c|}{ [Reference] } \\
\hline \multicolumn{4}{|l|}{ Sect } \\
\hline Sunnah & $0.485(0.318-0.740)$ & 0.105 & .001 \\
\hline Something Else & \multicolumn{3}{|c|}{ [Reference] } \\
\hline \multicolumn{4}{|l|}{ Health Insurance } \\
\hline No & $1.014(0.605-1.699)$ & 0.267 & .958 \\
\hline Yes & \multicolumn{3}{|c|}{ [Reference] } \\
\hline Income & $1.040(0.909-1.190)$ & 0.072 & .568 \\
\hline Age & 0.997 (0.976-1.019) & 0.108 & .800 \\
\hline Self-assessed Health & $0.986(0.977-0.996)$ & 0.005 & .005 \\
\hline \multicolumn{4}{|l|}{ Cognitive Factors } \\
\hline Knowledge & $1.405(1.098-1.798)$ & 0.177 & .007 \\
\hline Outcome Expectations & $1.257(0.901-1.754)$ & 0.214 & .178 \\
\hline Attitudes & $1.513(1.122-2.041)$ & 0.231 & .007 \\
\hline Perceived Value & $0.744(0.562-0.985)$ & 0.107 & .039 \\
\hline Self-efficacy & $1.011(0.998-1.023)$ & 0.006 & .091 \\
\hline \multicolumn{4}{|l|}{ Environmental Factors } \\
\hline \multicolumn{4}{|l|}{ Vicarious Learning - Family } \\
\hline No & $1.009(0.654-1.558)$ & 0.223 & .967 \\
\hline Yes & \multicolumn{3}{|c|}{ [Reference] } \\
\hline \multicolumn{4}{|l|}{ Vicarious Learning - Friends } \\
\hline No & $1.389(0.965-2.000)$ & 0.258 & .077 \\
\hline Yes & \multicolumn{3}{|c|}{ [Reference] } \\
\hline Social Norms - Family & $1.311(0.721-2.384)$ & 0.400 & .374 \\
\hline Social Norms - Friends & $1.024(0.778-1.349)$ & 0.144 & .863 \\
\hline Acculturation & $1.002(0.995-1.009)$ & 0.004 & .616 \\
\hline Religiosity & $1.011(1.002-1.020)$ & 0.005 & .016 \\
\hline Nicotine Dependence & $0.867(0.673-1.118)$ & 0.112 & .271 \\
\hline \multicolumn{4}{|l|}{ Tobacco Use Inside Home } \\
\hline Not allowed & $0.473(0.299-0.750)$ & 0.111 & .001 \\
\hline Allowed & \multicolumn{3}{|c|}{ [Reference] } \\
\hline \multicolumn{4}{|c|}{ Discuss Cigarette-smoking Cessation with Doctor } \\
\hline No & $0.957(0.641-1.428)$ & 0.196 & .828 \\
\hline Yes & \multicolumn{3}{|c|}{ [Reference] } \\
\hline
\end{tabular}

Abbreviations: AIRR, Adjusted Incident Rate Ratio, Cl, Confidence Interval, SE, Standard Error 